\title{
Myricetin: a Multifunctional Flavonol in Biomedicine
}

\author{
Gopikrishna Agraharam $^{1}$ (]) Agnishwar Girigoswami ${ }^{1}$ (i) $\cdot$ Koyeli Girigoswami $^{1}$ (])
}

Accepted: 17 November 2021 / Published online: 10 January 2022

(c) The Author(s), under exclusive licence to Springer Nature Switzerland AG 2022

\begin{abstract}
Purpose of Reveiw The root cause of many diseases like CVD, cancer, and aging is free radicals which exert their effect by interfering with different metabolic pathways. The sources of free radicals can be exogenous, like UV rays from sunlight, and endogenous due to different metabolic by-products.

In our body, there are defense mechanisms present, such as antioxidant enzymes and antioxidant molecules to combat these free radicals, but if there is an overload of these free radicals in our body, the defense system may not be sufficient to neutralize these free radicals. In such situations, we are exposed to a chronic low dose of oxidants creating oxidative stress, which is responsible for eliciting different diseases.

Recent Findings Pubmed and Google Scholar are the search engines used to sort out relevant papers on myricetin and its role in combating many diseases. Myricetin is present in many fruits and vegetables and is a known antioxidant. It can elevate the antioxidant enzyme levels; reduces the lipid peroxidation; and is known to protect against cancer. In the case of myocardial dysfunction, myricetin has been shown to suppress the inflammatory cytokines and reduced the mortality rate. Myricetin has also been found to reduce platelet aggregation and control the viral infections by interfering in the DNA replication pathways. Summary In this paper, we have briefly reviewed about the different type and site of free radicals and the role of myricetin in addressing the ROS and different diseases.
\end{abstract}

Keywords Free radicals $\cdot$ Myricetin $\cdot$ Cancer $\cdot$ Platelet aggregation $\cdot$ Myocardial dysfunction $\cdot$ Inflammation

Abbreviations
$\begin{array}{ll}\text { 4NQO } & \text { 4-Nitroquinoline 1-oxide } \\ \text { ASFV } & \text { African swine fever virus } \\ \text { BDE } & \text { Bond dissociation enthalpy } \\ \text { CAT } & \text { Catalase } \\ \text { EMT } & \text { Epithelial-mesenchymal transition } \\ \text { ETC } & \text { Electron transport chain } \\ \text { ETE } & \text { Electron transfer enthalpy } \\ \text { GPX } & \text { Glutathione peroxidase } \\ \text { HAT } & \text { Hydrogen atom transfer }\end{array}$

This article is part of the Topical Collection on Natural Products: From Chemistry to Pharmacology.

The editors would like to thank Dr. Sujit Nair for taking the time to review this manuscript.

Koyeli Girigoswami

koyelig@gmail.com; koyelig@care.edu.in

Faculty of Allied Health Sciences, Chettinad Hospital and Research Institute, Chettinad Academy of Research and Education, Kelambakkam 603103, Tamilnadu, India
HCC Hepatocellular carcinoma cells

IBD Inflammatory bowel disease

IP Ionization potential

MDA Malondialdehyde

NADP Nicotinamide adenine dinucleotide phosphate

NRCMs Neonatal rat cardiomyocytes

PA Proton affinity

PD Parkinson's disease

PDE Proton dissociation enthalpy

PLA2 Phospholipase A2

PQC Protein quality control

RA Rheumatoid arthritis

RCS Reactive carbon species

ROS Reactive oxygen species

SETPT Single electron transfer followed by proton transfer

SIMD Sepsis-induced myocardial dysfunction

SN Substantia nigra

SOD Superoxide dismutase

SPLET Sequential proton-loss electron-transfer 


\section{UVA Ultraviolet-A \\ ZIKV Zika virus}

\section{Introduction}

Myricetin falls under the group of flavonols along with quercetin, kaempferol, and isorhamnetin and is mainly found in the Myricaceae, Anacardiaceae, Polygonaceae, Pinaceae, and Primulaceae family and from consumables such as vegetables, fruits, and tea. It has shown potent activity against free radicals even at low concentrations compared to other flavonoids [103]. It is extracted as a solid form, appears yellow in color, has a molecular weight of about $318.23 \mathrm{~g} / \mathrm{mol}$ and has six hydrogen bond donors (https://pubchem.ncbi.nlm.nih.gov/compound/Myric etin). These characteristics of myricetin created special attention and demonstrated anti-photoaging activity and anticancer activity, antiplatelet aggregation activity, antihypertensive activity, immunomodulatory activity, anti-inflammatory activity, antiallergic activity, and analgesic activity and showed protective effects against many disorders $[103,112]$. This review is expected to give a brief understanding on the free radicals, reactive oxygen species (ROS), and its site of generation in the organism/ cell and the role of myricetin, a known antioxidant, in inhibiting ROS and its various pathways in inhibiting various diseases.

\section{Methodology}

This study was initiated with a search for literature relating to the antioxidants, free radicals, myricetin, myricetin on inflammation, myricetin on neurons, cancer, and platelet aggregation. Therefore, related articles between 1984 and 2020 were collected for this brief review from PubMed and Google scholar.

\section{Myricetin Structure}

Myricetin has two aromatic rings A and B in its structure that are combined by a three-carbon chain forming a cyclic ring $\mathrm{C}$, and reports suggest that the presence of more hydroxyl groups is one of the reasons of myricetin for being a potent antioxidant (Fig. 1) [27]. Structurally myricetin differs from quercetin with one extra hydroxyl at the 5'-OH of the phenyl moiety [115]. 2,3-double bond in the $\mathrm{C}$ ring increases the planarity of the molecule, accord higher rigidity and holds $\mathrm{A}$ and $\mathrm{C}$ rings in a coplanar position allowing 3-OH/4-O and 5-OH/4-O groups to be closer. Myricetin is the good reductant with six hydroxyl groups, catechol group in the $\mathrm{B}$ ring, 3-hydroxyl group, 2,3-double bond, and 4-oxo group in the $\mathrm{C}$ ring which is also important for its reducing activity [78]. The presence of a 3-hydroxyl group on ring $\mathrm{C}$ and the presence of 4-hydroxyl group on ring B might affect the metabolism or absorption of myricetin [114]. Efficacy of the physical quenching is mainly controlled by the catechol moiety of the $\mathrm{B}$ ring, whereas the presence of the 3-OH group which activates 2,3-double bond on the ring $\mathrm{C}$ is the main factor for determining the chemical reactivity with ${ }^{1} \mathrm{O}_{2}$. 3-OH group at the $\mathrm{C}$ ring shows the low reactivity and the quenching rate $\left(\mathrm{k}_{\mathrm{Q}}\right)$ value of myricetin is 5.12 $1018 \mathrm{M}^{-1} \mathrm{~s}^{-1}$ for ${ }^{1} \mathrm{O}_{2}$ oxygen, which is higher than quercetin, rutin, and apigenin [80]. Figure 1 shows the $2 \mathrm{D}$ structure of myricetin.

\section{Source of Myricetin}

Myricetin widely occurs in nature in berries, vegetables, and fruits, in the form of glycosides rather than free aglycones [83]. $57.2 \mathrm{mg}$ of myricetin/g was extracted from the

Fig. 1 Myricetin 2D structure

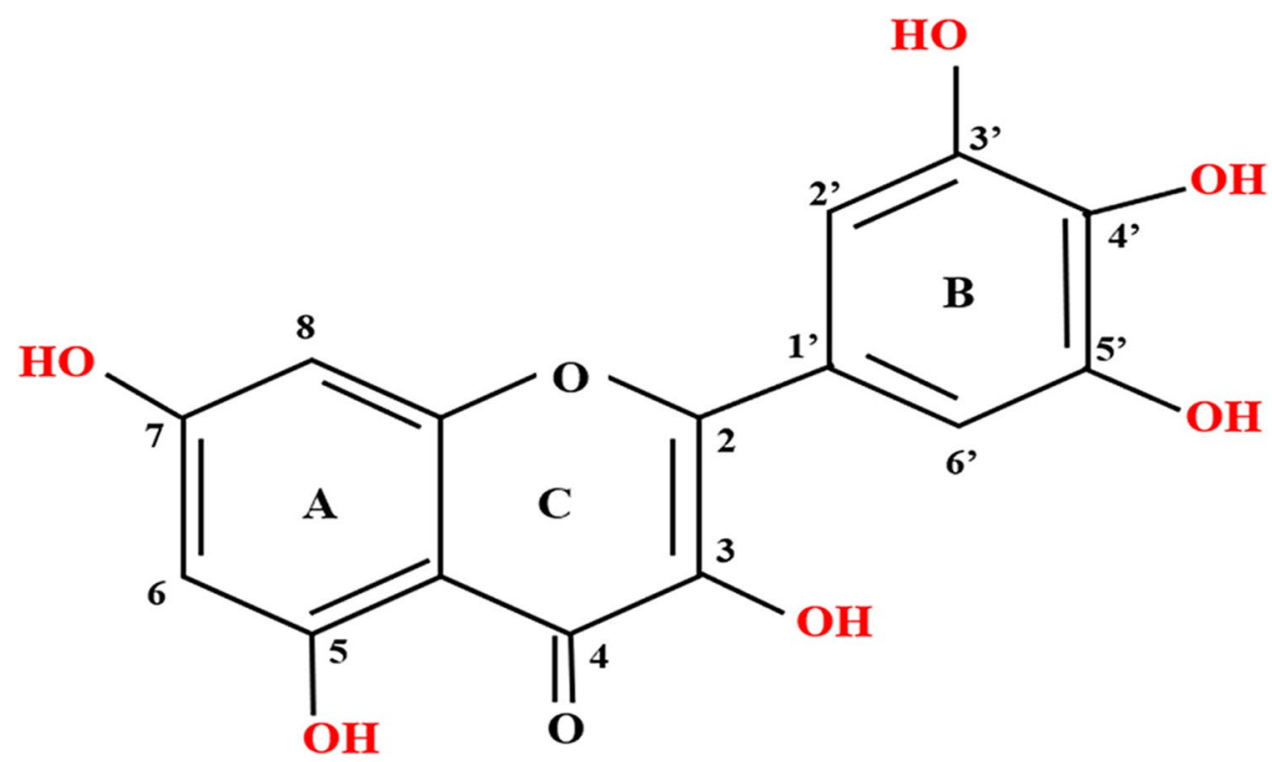


Lycium barbarum L. fruits [2], and it is found in the Carménère grape's skin and has high concentrations of myricetin $(2.4 \mathrm{mg} / \mathrm{kg})$ than other grape species [42], whereas bambara groundnut (Vigna subterrania) has $1800 \mathrm{mg} \mathrm{g}^{-1}$ of myricetin [41]. Content of myricetin in some of the fruits and vegetables is given in Table 1 . Lin et al. extracted around $188 \mathrm{mg} / \mathrm{kg}$ of myricetin from the dry aerial parts of the plant Limonium sinense along with myricetin glycosides, myricetin 3-O- $\alpha$-rhamnopyrano $(309 \mathrm{mg} / \mathrm{kg}$ ), myricetin $3-O-\beta$-galactopyranoside $(63 \mathrm{mg} / \mathrm{kg})$, and myricetin $3-O-\beta$-arabinopyranoside $(18 \mathrm{mg} / \mathrm{kg})$ [69]. Reports indicated that myricetin and myricetin glycosides can also be found in flowers of white clover (Trifolium repens $L$.), leaves of Acasia confuse [31, 62]. Braca et al. extracted seven types of myricetin glycosides are myricetin 3'-methylether-3-O-glucoside, myricetin 3'-methylether-3-Ogalactoside, myricetin 4'-methylether-3- $O$-rhamnoside, myricetin 3',5'-dimethylether-3-O-glucoside, myricetin 3',5'-dimethylether-3- $O$-rhamnoside, myricetin 3',4'-dimethyl ether 3-O- $\beta$-D-glucopyranoside, and myricetin 3-O- $\alpha-$ $\mathrm{L}-(2 "-O-\alpha$-L-rhamnopyranosyl)-rhamnopyranoside from the dried leaves of plant Licania densiflora $[11,12,97]$. Chemical synthesis of myricetin process can form myricetin as the final product by the steps such as hydrolysis, demethylation, methylation by using other constituents $[52,97$, 103]. Tolosa et al. reported an optimized acid hydrolysis of myricetin-3-O-rhamnoside to yield myricetin [111]. Table 1 shows content of myricetin and its glycosides in fruits, vegetables, and plant parts.

\section{Oxidants and Antioxidants}

A free radical is an unstable molecule comprising of unpaired electron or electrons that acquires high reactiveness and reacts either with a radical to form a stable molecule or with a non-radical to form a new radical [39]. In aerobic eukaryotes, the consumed oxygen is reduced to water and releases superoxide radical $\mathrm{O}_{2} \cdot{ }^{-}$and hydroxyl radical $\left(\mathrm{OH}^{-}\right)$that damages the biomolecules. $\mathrm{H}_{2} \mathrm{O}_{2}$ is not a radical although for possessing high reactivity, it is included in ROS generators [71]. Superoxide generation was reported in muscle cells by NADP/H oxidase, electron transport chain (ETC) of mitochondria, phospholipase A2 (PLA2), calcium-dependent PLA2, xanthine oxidase, and nitrogen radical (NO') generated in the process of nitric oxide

Table 1 Content of myricetin and its glycosides in fruits, vegetables, and plant parts

\begin{tabular}{|c|c|c|c|c|}
\hline S/no & $\begin{array}{l}\text { Common name of source } \\
\text { (fruit/vegetables) }\end{array}$ & Scientific name & $\begin{array}{l}\text { Content } \mathrm{mg} / \mathrm{Kg} \text { of fresh weight (for fruits) and } \\
\mathrm{mg} / \mathrm{Kg} \text { of dry weight (for vegetables) }\end{array}$ & Citation \\
\hline 1 & Black currant & Ribes nigrum $O^{*}$ jebyn & 71 & [38] \\
\hline 2 & Cranberry & Vaccinium oxycoccos (wild) & 74,142 & [38] \\
\hline 3 & Bilberry & Vaccinium myrtillus (wild) & 14,21 & [38] \\
\hline 4 & Blueberry & Vaccinium corymbosum Northcountry & 26 & {$[38]$} \\
\hline 5 & Blueberry & Vaccinium corymbosum Northblue & 23 & {$[38]$} \\
\hline 6 & Crowberry & Empetrum hermaphroditum (wild) & 49 & {$[38]$} \\
\hline 7 & Crowberry & Empetrum nigrum (wild) & 44 & {$[38]$} \\
\hline 8 & Green chili & Capsicum annum & 11.5 & [77] \\
\hline 9 & Red chili & Capsicum annum & 29.5 & {$[77]$} \\
\hline 10 & Bell pepper & Capsicum annum & 171.5 & [77] \\
\hline 11 & Garlic & Allium sativum & 693 & [77] \\
\hline 12 & Lady’s fingers & Hibiscus esculentus & 54.5 & {$[77]$} \\
\hline 13 & Brinjal & Solanum melongena & 39.5 & [77] \\
\hline 14 & Guava & Psidium guajava & 549.5 & [77] \\
\hline 15 & Black tea & Camellia chinensis & 303 & [77] \\
\hline 16 & Cabbage & Brassica oleracea & 147.5 & [77] \\
\hline 17 & Wolf berry & Lycium barbarum $L$. fruits & $57 \mathrm{~g}$ & [2] \\
\hline 18 & Carménère grape's & Vitis vinifera 'Carménère' & 2.4 & [42] \\
\hline 19 & Bambara groundnut & Vigna subterrania & $1800 \mathrm{mg} \mathrm{g}^{-1}$ & [41] \\
\hline 20 & Sea-lavender (aerial parts) & Limonium sinense & 188 & [69] \\
\hline 21 & White clover (flowers) & Trifolium repens $L$ & 216 & {$[31]$} \\
\hline 22 & Formosan-koa (leaves) & Acasia confuse & 1502.5 & {$[62]$} \\
\hline
\end{tabular}

Table 1 was recreated from [38], and [77] 
synthesis, and these oxygen-centered radicals are grouped into reactive oxygen species (ROS) [39, 45]. Ultraviolet-A (UV-A) irradiation can potentially generate carbon radicals (carbon-centered radicals, reactive carbon species (RCS)) and hydroxyl radicals and damage nucleic acids in the skin cells/low pigmented (low melanin) skin cells [53].

Oxidative stress is an imbalance of antioxidants and oxidants in the organism or cell that disrupts redox signalling and its control that leads to damage of cellular macromolecules [104]. Chronic low-dose exposure to oxidants such as hydrogen peroxide and cisplatin modifies the sensitivity of cells, whereas the effect of UV light is unchanged in mammalian cells [8]. The effect of chronic low-dose exposure of oxidative stress induced resistance in cells with elevated antioxidant enzyme levels (catalase (CAT), glutathione peroxidase (GPx), superoxide dismutase (SOD)) [9], and inhibited apoptosis with adaptive error-prone repair when exposed to gamma rays [10]. The mitochondrial enzyme, NADH dehydrogenase, was overexpressed in chronic low dose of hydrogen peroxide exposed cells [36]. Long-term low-dose exposure to hydrogen peroxide contributed complementary resistance to cisplatin through the inhibition of apoptosis in these cells [35]. The oxidative stress can be termed differently as dietary oxidative stress, physiological oxidative stress, photooxidative stress, radiation-induced oxidative stress, oxidant stress, prooxidant stress, oxidative stress status, reductive stress, and nitrosative stress depending on the sources of free radicals [105].

Antioxidants neutralize free radicals and suppress oxidative stress in the organism or cells. Natural and synthetic antioxidants are majorly found as two types, endogenous antioxidants such as glutathione peroxidase, superoxide dismutase, catalase, and vitamin $\mathrm{A}$ and $\mathrm{C}$ and exogenous antioxidants such as vitamin $\mathrm{E}$ and carotenoids, that protect organisms from oxidative stress [82, 99]. Ellagic acid and its derivatives that contain catechol or guaiacyl moieties are shown to scavenge free radicals by hydrogen atom/ proton loss sequence [129]. The polyphenols extracted from plants and plant products may not always produce any protective agents. Researchers have found cytotoxic polyphenols from the fruits of Psoralea corylifolia, and nearly 17 such meroterpene phenols were described [119], but most of the polyphenols are found to have protective effects against many diseases.

Flavonoids are natural antioxidants by their structure and are found in vegetables, tea, cocoa/chocolate, olive, onion, grapes/wine, berries, and fruits [92]. Flavonoids were proven to show many protective effects from many diseases such as cardiovascular diseases, age-related disease, and oxidative stress-induced damages by their antioxidant activity and showed anti-inflammatory, antiviral, and antiproliferative effects [120]. The antioxidant properties of flavonoids were studied by researchers where the reaction enthalpies linked to sequential proton-loss electron-transfer (SPLET) mechanism were explored theoretically for many mono-deprotonated forms of flavonoids and it was found that in aqueous solution these deprotonated flavonoids prefer to enter the SPELT mechanism rather than hydrogen atom transfer (HAT) or mechanism of electron transfer [6]. Flavonoids belong to the polyphenolic group of phytochemicals and are further classified into isoflavones, neoflavones, chalcones, flavones, flavonols, flavonones, flavonols, and so on based on their chemical structure [112]112, 112]. Myricetin is a kind of flavanol that can play role in the management of various diseases by acting as a free radical scavenger as well as a prooxidant.

\section{Antioxidant Activity of Myricetin}

Many studies have indicated the antioxidative capacity of myricetin that included (i) a less $\mathrm{O}-\mathrm{H}$ bond dissociation enthalpy (BDE) which eases the $\mathrm{H}$ abstraction; (ii) an enhanced ionization potential (IP) that hampers the reduction of oxygen by the antioxidant; and (iii) a sufficient solubility. In a study, a semi-empirical experiment was done in the gas and water phase of myricetin using PM6 Hamiltonian, and the derived radicals were also considered along with the anionic species. The structural and the electronic features which are responsible for the antioxidant activity of myricetin were elucidated by three mechanisms that can be possible: (i) $\mathrm{H}$ atom abstraction (HAT), (ii) single electron transfer followed by proton transfer (SETPT), and (iii) sequential proton loss electron transfer (SPELT). The mechanisms are shown in Fig. 2. The BDE, proton affinity (PA), and the electron transfer enthalpy (ETE) from the anion as

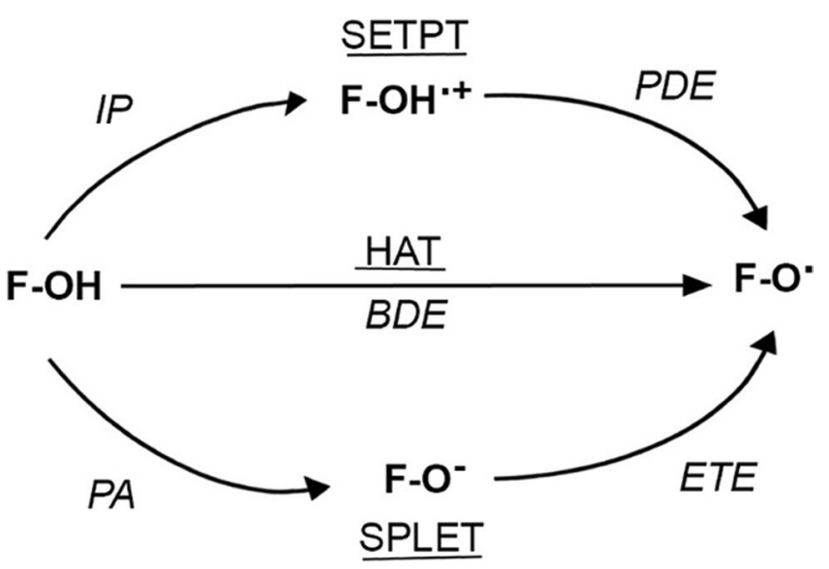

Fig. 2 The representative scheme depicting the antioxidant activity of myricetin (SPLET, sequential proton loss-electron transfer; SETPT, sequential electron transfer-proton transfer; PA, proton affinity; PDE, proton dissociation enthalpy; ETE, electron transfer enthalpy; BDE, bond dissociation enthalpy) 
well as the proton dissociation enthalpy (PDE) from the cation radical were estimated. The calculations were done by finding the heats of formation (Hf) differences between the products and the reactants (Fig. 2), in which F-O• and F-O- represent the radical and the anion obtained from the antioxidant (F-OH), respectively. The values thus obtained make the three proposed antioxidant mechanisms of myricetin relevant. The mechanisms are (i) HAT which can be quantified by BDE; (ii) SETPT calculated by IP and PDE; and (iii) SPLET which can be quantified by the proton affinity and the ETE (Fig. 2) [29, 51, 55, 70, 124].

A low concentration of myricetin $(10 \mu \mathrm{m})$ showed a potential role in inhibiting LDL oxidation by macrophages, where the same inhibiting effect was showed by a higher concentration of flavone and gossypin $(100 \mu \mathrm{m})$ [24]. Myricetin showed a protective effect from ${ }^{1} \mathrm{O}_{2}$ induced DNA damage in vitro on plasmid pBR 322 DNA [26]. Myricetin is also capable of inhibiting divalent metal-ion induced lipid peroxidation [96]. Myricetin greatly reduced $\mathrm{Ca}^{2+}$-dependent DCFH oxidation and DCF fluorescence in brain neurons [88]. In a study, it was found that out of 33 flavonoids myricetin is more potent and inhibited ATP-dependent $\mathrm{Ca}^{2+}$ uptake by the liver plasma membrane vesicles [110], and it inhibited the $\mathrm{Ca}^{2+}$ - ATPase of disrupted human erythrocyte plasma membranes [109]. In vitro study on MCF-7 breast cancer cells also exhibited antioxidant properties of myricetin through the DCF method. Myricetin reduced the fluorescence activity of DCF which indicated decreased oxidation of DCF and ROS scavenging activity of Myricetin [5]. In our recent study, we found that nano-encapsulated myricetin elevated antioxidant enzyme levels (Glutathione peroxidase, superoxide dismutase, catalase) in hydrogen peroxide treated zebrafish embryos (unpublished data) which indicated the antioxidant activity of myricetin.

\section{Prooxidant Activity of Myricetin}

In living organisms, transition metals like iron and copper exist in two stable oxidative forms, such as ferrous $\left(\mathrm{Fe}^{2+}\right)$, ferric $\left(\mathrm{Fe}^{3+}\right)$ and cuprous $\left(\mathrm{Cu}^{1+}\right)$, cupric $\left(\mathrm{Cu}^{2+}\right)$, respectively [3]. In liver and brain cells, copper $(\mathrm{Cu})$ is present in high concentrations, and several enzymes are bound with copper such as cytochrome c, $\mathrm{Cu}-\mathrm{Zn}$-superoxide dismutase, lysyl oxidase, and ferroxidase I that are involved in many biological processes [34]. Iron plays a vital role in the living organisms such as oxygen binding and transport, cellular respiration, electron transport, drug metabolism, and steroid synthesis [89]. So, it is important to consider imbalance of metal homeostasis in the treatment of flavonoids. Myricetin was found to exhibit prooxidant activity in the presence of metal ions. The antioxidant activity of myricetin in the presence of iron and copper salt was explored using sunflower oil and emulsions made from oil-in-water. The prooxidant effect of cupric chloride mixed in oil-in-water was enhanced by myricetin at $\mathrm{pH}=7.4$, but it did not enhance the prooxidant effect of cupric stearate. A strong prooxidant effect was observed when myricetin was added to ferric chloride containing emulsions at $\mathrm{pH}=5.4$. On the other hand, myricetin was found to reduce the prooxidant effect of the ferric palmate in oils and acted as a strong antioxidant in oils containing cupric stearate. Thus, myricetin was found to exert prooxidant activity in the metal salt presence, but the kind of metal salt present is vital to determine whether it will become a prooxidant or antioxidant [98]. Myricetin is a powerful inhibitor of lipid peroxidation induced by iron in rat liver, but it generated eight-fold increased hydroxyl radical from $\mathrm{H}_{2} \mathrm{O}_{2}$ in the presence of $\mathrm{Fe}^{3+}$ - EDTA, $\mathrm{pH}=7.4$. There was an acceleration of bleomycin-induced DNA damage in the presence of $\mathrm{Fe}^{3+}$, induced by $75 \mu \mathrm{M}$ myricetin. Thus, the prooxidant effect was also revealed along with the antioxidant effect of myricetin [60]. In bleomycin- $\mathrm{Fe}^{3+}$ induced DNA damage, and the amount of DNA damage increased with myricetin concentration, then declined with further increase in concentration [59]. In the presence of myricetin, iron (III) and copper (II) can undergo redox reactions and can generate ROS, causing DNA damage in the rat liver cells [101]. Myricetin is vulnerable to autooxidation at $\mathrm{pH}$ over than 7.4 which could lead to the release of ROS and can exert a toxic effect on the biomolecules [14]. Myricetin generates $\mathrm{H}_{2} \mathrm{O}_{2}$ by autooxidation and then by Fenton reaction, and generates $\mathrm{OH}^{-}$radicals in the presence of $\mathrm{Fe}^{2+}$ [40]. Increased number of hydroxyl groups on the B-ring of flavonoids can cause increased DNA damage if the release of hydroxyl radical is close to the DNA and myricetin showed a potent effect in damaging DNA [1]. At a lower dose, myricetin was found to be potent in inhibiting 4-nitroquinoline 1-oxide(4NQO) and cigarette smokeinduced mutagenicity, but at the same time, higher doses caused mutagenicity in the TA98 strain of S. typhimurium with S9 mix [13, 30]. Myricetin showed a deleterious effect on the DNA topoisomerase I and II and also exhibited an antagonistic effect on the genistein-induced topoisomerase-mediated DNA cleavage [4]. In a comparative study of flavanols, the prooxidant and antioxidant activity of myricetin was discussed, and it was found that in an aqueous environment myricetin can act as a potent free radical scavenger. The prooxidant activity of a flavonoid molecule is directly proportional to the total hydroxyl groups present in that molecule. Mono- and dihydroxyl flavonoids did not show any prooxidant activity, whereas multiple hydroxyl groups containing flavonoids, specifically attached with the B-ring, could increase the production of hydroxyl radical significantly through the Fenton reaction. In vivo, the presence of free metal ions may trigger the oxidation process along with the flavonoids. The flavonoids can reduce $\mathrm{Cu}$ (II) to $\mathrm{Cu}(\mathrm{I})$ and initiate the free radical formation. In healthy 
conditions, the metal ions are sequestered and cannot catalyze the free radical reactions, but in injured tissues, the tissues can release more iron or copper that can catalyze the free radical reactions and then the flavonoids can act as a prooxidant [93]. Researchers have compared the prooxidant and antioxidant activity of myricetin in the presence and absence of ascorbic acid using a deoxyribose degradation assay. In the presence of ascorbic acid, myricetin exhibited antioxidant properties, specifically when it happened in complex with iron. But the prooxidant activity of myricetin prevailed in the absence of ascorbic acid and was enhanced in the presence of iron complexed with EDTA. Thus, the findings showed that the antioxidant activity of myricetin is dependent both on the ROS scavenging and the chelating properties of iron ions. On the other hand, the prooxidant activity was exhibited due to the molecular oxygen reduction to ROS and iron (III) to iron (II) [17]. Different photophysical tools were used to compare the antioxidant and prooxidant activity of multiple hydroxyl groups containing flavonoids which included myricetin also. The EPR and UV-vis spectroscopic results indicated that myricetin interacts with cupric ions through 3-OH and 4-CO groups of C-ring and unsaturated $\mathrm{C} 2-\mathrm{C} 3$ bonds in the $\mathrm{C}$-ring and 3',4',5'-OH groups of B-ring. The DNA binding affinity of the flavonoids can be modulated by copper ions through the $\mathrm{Cu}$-chelate formation and myricetin has the lowest protective effect. The prooxidant effect of myricetin can cause DNA damage by ROS formation through Fenton reaction, and the damage was pronounced in flavonoids with a higher number of hydroxyl groups. Thus, this property can enhance anticancer effect where cell death can be achieved through high production of free radicals by myricetin in the proper environment [48]. In supporting to previous studies, Mandic et al. claimed that myricetin contributes to the increase in the toxic effect of copper and increased ROS generation, depleted GSH content, and reduced cell viability of neuroblastoma cells (SH-SY5Y cells) indicating that myricetin might form intercalation with transition metals (iron, copper) and acquires capabilities to induce DNA damage [73].

\section{Effect of Myricetin on Various Diseases}

\section{Cancer}

A high concentration of myricetin $(200 \mu \mathrm{M})$ protected mice from DSS-induced colitis, showed increased SOD activity and decreased malondialdehyde (MDA) [128]. Reports indicated that myricetin can induce autophagy and apoptosis of cancer cells by regulating ER stress, bcl-2 through GRP-78, survivin, BAD, NF-kB, mTOR through AKT gene, topoisomerase I and II, hTERT
mRNA and telomerase [46]. Myricetin inhibited the proliferation, induced apoptosis, and arrested the cell cycle of OVCAR-3 and SKOV-3 cells, and its effect was more on metastatic ovarian cancer cells than the primary ovarian cell [108]. Myricetin inhibited the viability of breast cancer cells, suppressed breast cancer lung metastasis by inhibiting MMP-2 and MMP-9 in vivo, reduced ST6GALNAC5 mRNA expression, and inhibited migration, invasion, and adhesion in MDA-Mb-231Br cells in vitro [20]. Myricetin augmented radio sensitization of tumor cells in vitro by inhibiting lung cancer A549 and H1299 cells' proliferation and increased apoptosis by caspase- 3 expression and was also found to be efficient in sensitizing lung cancer cells to radiotherapy in mice [127]. An induced cell cycle progression, nuclear condensation, and cell death of SNU-790 human papillary thyroid cancer (HPTC) cells by disrupting mitochondria and regulating caspase-dependent pathways were exhibited by myricetin treatment [37]. Myricetin was found to inhibit the growth of TNBC cell lines by oxidative stress-mediated apoptosis which is generated by myricetin-induced $\mathrm{H}_{2} \mathrm{O}_{2}$ in the extracellular environment [56]. Myricetin was found to arrest the G0/G1 phase of the cell cycle, inhibited the progression of the cell cycle by binding to the NTD of RSK2, promoted apoptosis by overexpressing Bad protein, and inhibited proliferation by overexpressing Mad1 protein in the oesophageal carcinoma cells EC9706, KYSE30 [123]. Myricetin induced apoptosis, inhibited invasion, migration, epithelial-mesenchymal transition (EMT), phosphorylation of ERK1/2, and AKT, suppressed tumor progression by up-regulating E-cadherins and down-regulating $\mathrm{N}$-cadherins and vimentin and inhibited the CXCL12/ CXCR4 axis through inhibiting PIM1 in prostate cancer cells [121]. Myricetin suppressed the cell viability, colony formation, proliferation, and induced apoptosis by down-regulating YAP through regulating kinase activity of LATS/2 in hepatocellular carcinoma cells (HCC) [65]. Myricetin decreased the viability and induced apoptosis of ovarian cancer cells by up-regulation of Bax, Bad, p53, and $\mathrm{p} 21$ proteins and by the down-regulation of c-Myc [43]. Intake of flavonoids (flavonoids rich food) did not show protective effect on cancer, particularly site-specific cancer [116]. Myricetin caused cell death in lung cancer cells (A549 cells) through chromatin condensation, nuclear fragmentation, and cell shrinkage and depolarizing the mitochondrial lining membrane. Myricetin also increased ROS in A549 cells, up-regulated p53 levels and down-regulated EGFR, and moreover, molecular docking results revealed that $\mathrm{p} 53$ and EGFR have strong interaction with OH-sites of the myricetin [95]. The different mechanism of cell death proposed to be induced by myricetin is shown in Fig. 3. 
Fig. 3 Cell death mechanism of Myricetin in cancer cells

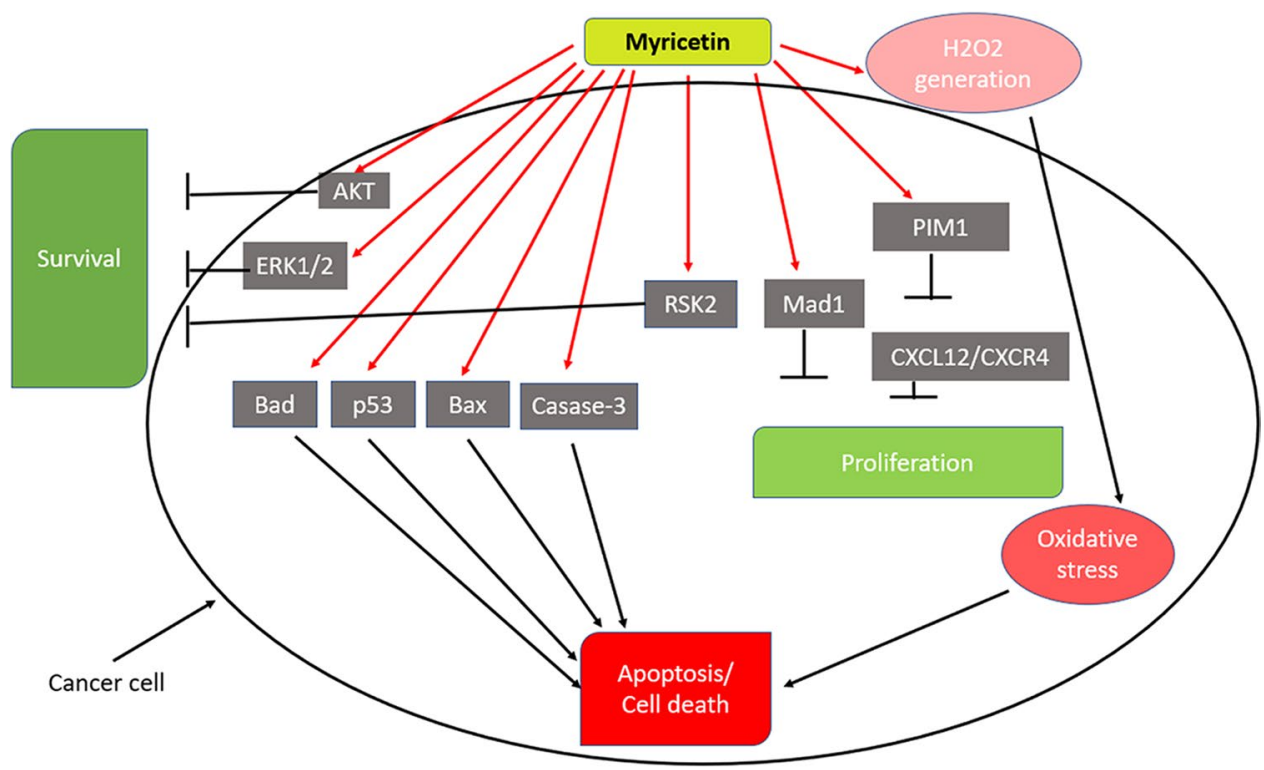

\section{Myocardial Dysfunction}

In an earlier study, Michael et al. concluded that the intake of flavonoids lowered coronary heart disease mortality rates [76]. Myricetin lowered the LPS-induced myocardial dysfunction by inhibiting inflammatory cytokines IL-27, IL-17A, IL-6, IL-23, IL-1a, IFN- $\gamma$, TNF- $\alpha$, MCP-1, IL$12 \mathrm{P} 70, \mathrm{IL}-1 \beta$, INF- $\beta$, and GM-CSF, inhibited translocation of p65 and decreased the expression of iNOS and oxidative stress $[15,126]$. Myricetin attenuated apoptosis by down-regulating c-caspase-3 and Bax and prevented degradation of IkB $\alpha$ in LPS-induced SIMD (sepsis-induced myocardial dysfunction) [15, 126]. Myricetin also showed antiatherosclerosis effect by reduction of LDL oxidation and by inhibiting the uptake of oxidized LDL by macrophages [102]. Myricetin improved ischemia/reperfusion altered cardiac function,decreased myocardial injury and apoptotic cardiomyocytes by suppressing inflammatory cytokines such as TNA-a, IL-6, CRP, decreased activity of CYP, COX-2, and p38, and increased activity of FASN and G6PD [94]. Myricetin treatment blocked the JNK1/2, p38 over activation, inhibited the TRAF6/TAK1/MAPK pathway, and attenuated the pathological cardiac hypertrophy and fibrosis by reducing the hypertrophy markers and fibrosis markers. Myr-mediated Nrf2 expression prevented $\mathrm{H}_{2} \mathrm{O}_{2}$-induced oxidative stress in NRCMs (neonatal rat cardiomyocytes) [67]. The different protection mechanism of myricetin on cardiomyocytes is represented in Fig. 4.
Fig. 4 Protection mechanism of Myricetin in cardiomyocytes

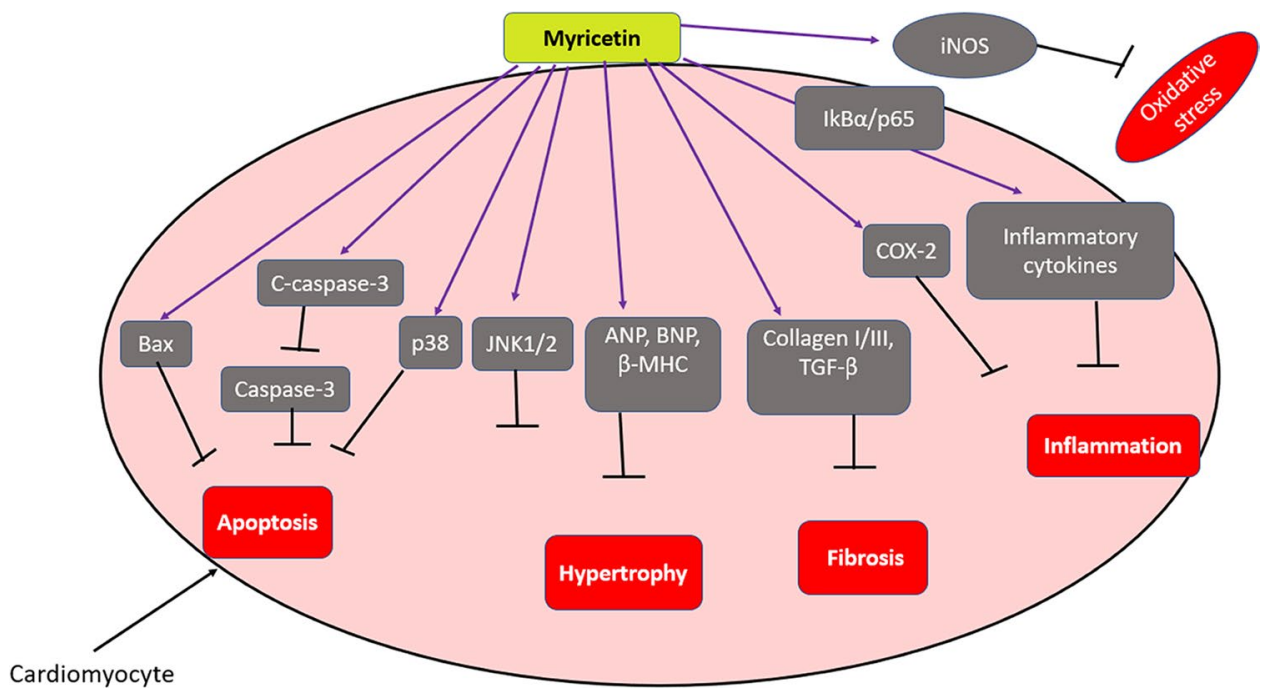




\section{Platelet Aggregation}

Purple grape juice inhibited platelet aggregation in monkeys and dogs in vivo and ex vivo, but grapefruit and orange did not show any effect on platelet aggregation [87]. Myricetin inhibited collagen-induced platelet aggregation, PAFinduced platelet aggregation, and ADP-induced washed rabbit platelet aggregation [113]. Myricetin was found to inhibit the platelet activity in humans by decreasing the calcium mobilization and TXB2 levels, but myricetin did not show any potent effect in inhibiting COX1/COX2 gene expression $[44,64]$. Myricetin reduced fibrinogen binding and alpha granule secretion induced by CRP, decreased thrombus formation, and exhibited the ability to inhibit platelet activity by inhibiting the activity of thiol isomerases and reductase activity of PDI and Erp5 [33]. In another study, it was seen that myricetin decreased the platelet aggregation by blocking cyclooxygenase and lipoxygenase pathways, increased the platelet cyclic AMP and inhibited AA metabolism [58]. The beneficial role of myricetin in platelet aggregation is schematically represented in Fig. 5.

\section{Viral Infections}

Reports indicated that myricetin slightly inhibited eukaryotic beta and gamma polymerase and competitively and noncompetitively inhibited $E$. coli RNA polymerases and inhibited HIV as well as RLV retroviral transcriptase and MMLV reverse transcriptase enzymes. It was also found that it was needed in 10-to-30-fold high concentration than that required to inhibit MMLV RT, to inhibit DNA polymerase I, indicating the antiviral property of myricetin and its low cytotoxicity to host cells $[19,84,85])$. A free hydroxyl group at position 3 is important for the mutagenic activity of myricetin [50].
The host antiviral immunity suppressing protein EBOV-VP35 in the Ebola virus was inhibited by myricetin through binding to VP35-dsRNA binding pocket [22]. nsP13 helicase is important for SARS-corona virus replication in the host cell [54]. Myricetin inhibited ATP hydrolase activity of nsP13 helicase of SARC-CoV to more than $90 \%$ at low concentration $(10 \mu \mathrm{M})$, but myricetin did not inhibit HCV helicase [74, 122]. Myricetin has anti-HSV-1 and HSV-2 (herpes simplex virus) activity by inhibiting the EGFR/PI3K pathway and reduced activity of Akt through blocking the gD protein in vivo [66]. The authors concluded that myricetin binding to $\mathrm{gD}$ protein thereby interferes in virus adsorption and membrane fusion, inhibits HSV replication in Hep-2 cells and HeLa cells, and pre-treatment of HSV with myricetin reduced the number of plaques [66, 72]. Myricetin inhibited HIV1 infection by inhibiting HIV1 reverse transcriptase at $100 \mu \mathrm{M}$ concentration [91]. African swine fever virus (ASFV) protease was inhibited by myricetin which elicited that it may protect from ASFV infection [47]. Myricetin inhibited ZIKV NS2B-NS3 protease, Zika virus replication, and decreased ZIKV plaques in a concentration-dependent manner, but the effect was observed immediately after infection, and after $1 \mathrm{~h}$ of infection, it showed moderate inhibition $[68,130]$. Through virtual analysis, myricetin showed higher binding affinity with SARS-CoV2 $\mathrm{M}^{\text {pro }}$ and exhibited significant inhibition in FRET based assay, but further studies are needed to understand the myricetin effect on SARS-CoV2 [118]. The different mechanisms of viral infection inhibition by myricetin are shown in Fig. 6.

\section{Inflammation}

Inflammation is one of the major phenomena that is involved in the pathophysiology of major diseases such as rheumatoid
Fig. 5 Role of Myricetin in platelet aggregation

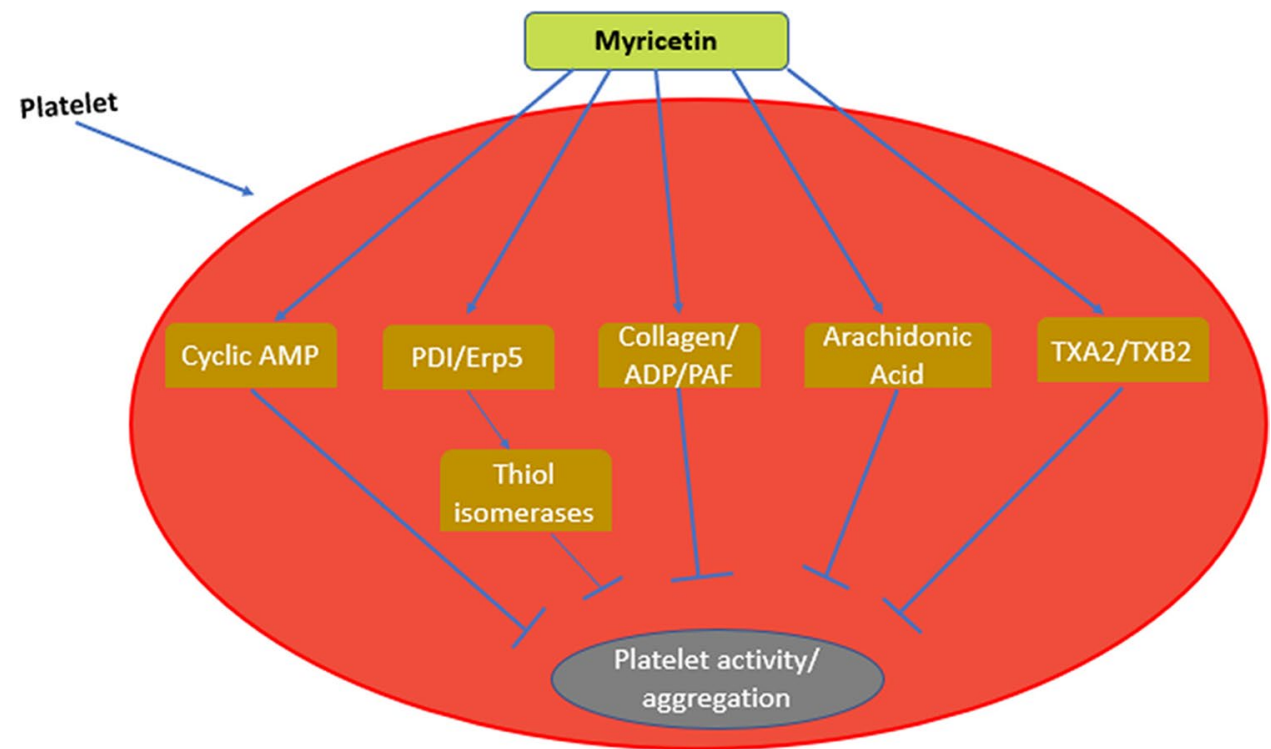


Fig. 6 Mechanism of myricetin inhibition for various viral infections

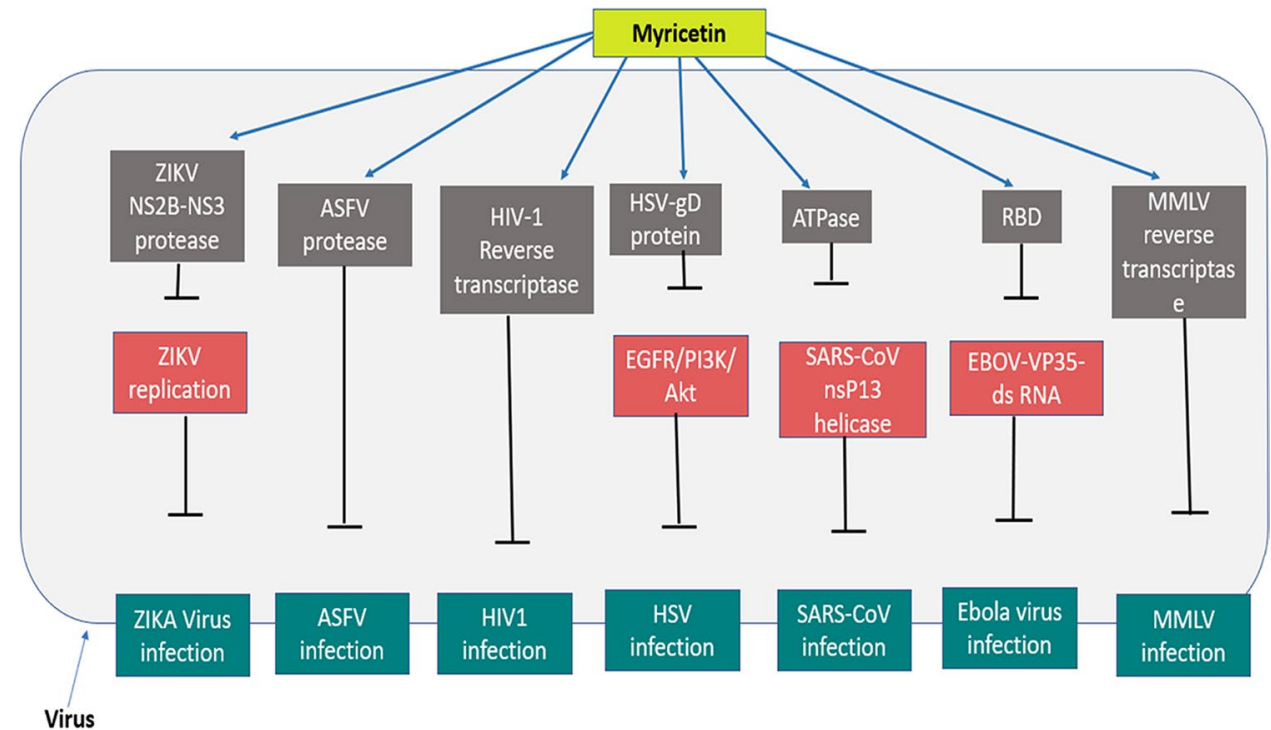

arthritis (RA), inflammatory bowel disease (IBD), and cardiac diseases, etc. Flavanols that have hydroxyl groups on the positions of A-5, A-7, B-4' are shown to have TNF- $\alpha$ inhibitory activity. Myricetin inhibited TNF- $\alpha$ production in vitro but orally administered myricetin to mice did not inhibit serum TNF- $\alpha$ production and TPA-induced ear oedema in vivo which might be due to the lower bioavailability (Ueda 2004). Myricetin treatment exhibited increased ALP activity and inhibited Fas up-regulation, blocking anti-Fas IgM-mediated apoptosis and the synergic apoptotic effect of TNF- $\alpha$ and IL- $1 \beta$ in MG-63 osteoblast cells in vitro [57]. Thrombin activity was inhibited by myricetin [75]. Myricetin inhibited the release of histamine and decreased intracellular calcium levels, TNF- $\alpha$ and IL- 6 in vitro [90], decreased MDA levels, and increased SOD activity in vivo in rats which indicated that apart from inflammatory cytokines, myricetin can suppress free radicals through elevating antioxidant enzymes [117]. Pre-treatment with myricetin decreased the up-regulation of MMP-1 and IL6 , and inhibited the phosphorylation of p38 and JNK in the human synovial sarcoma in vitro [63]. Corroborating with the previous studies, myricetin treatment decreased secretion of TNF-alpha, IL-6, and IL-12p70 in a concentrationdependent manner, also found to inhibit CD86, CD40, and MHC-II markers,decreased migration of dendritic cells and NF- $\kappa \mathrm{B}$ p65 levels and disrupted NF- $\mathrm{BB}$ and MAPK pathways through blocking IKK and JNK p38 activities which are also involved in dendritic cell maturation in lipopolysaccharide-stimulated mBM-dendritic cell and RAW 264.7 macrophages [16, 21, 32]. AST, 4-HNE, and TBARS levels were decreased by myricetin, and reduced glutathione levels were restored to normal level in $\mathrm{CCl}_{4}$-induced liver damage in mice [28]. Myricetin was found to suppress NF-kB by suppressing the inflammatory mediators Akt and mTOR through down-regulating TNF- $\alpha$ in keratinocytes in vitro [61]. Figure 7 shows the different pathways by which myricetin can inhibit inflammation.

\section{Neurodegenerative Diseases}

ROS, oxidative stress, and iron accumulation in the substantia nigra (SN) are some of the main causes for death and degeneration of dopaminergic neurons in the Parkinson's disease (PD). Myricetin treatment inhibited rotenone-induced hepcidin expression,increased Fpn1 expression and inhibited STAT3 and SMAD1 in rotenone-treated MES23.5 dopaminergic cells. Pre-treatment with myricetin also increased cell viability and reduced the ROS production [25]. Myricetin attenuated MMP + induced cytotoxicity and cell apoptosis, ROS production, caspase-3 activity, phosphorylation of MKK4, and JNK protein expression, increased Bcl-2 expression, and decreased Bax in MES23.5 cells in vitro [125]. Pre-treatment with myricetin inhibited iNOS and COX2 expression and counteracted CD68, decreased the phosphorylation of Tyr701, and inhibited STAT-1 and its translocation into nucleus of hypoxia exposed BV2 cells in a dose-dependent manner, indicating that myricetin can inhibit hypoxia-induced microglia M1 activation [7]. At lower doses $(50 \mu \mathrm{M})$ myricetin showed protective effect and decreased $21 \%$ of caspase-3 activity against rotenone-induced cytotoxicity in SH-SY5Y cells [79]. A $\beta$-mediated oxidative stress is involved in the pathogenesis of Alzheimer's disease, and the treatment with myricetin decreased the LDH release and protected from cell death in $A \beta_{25-35}$-induced neuronal cells [18]. Treatment of neurons with myricetin significantly reduced $\mathrm{A} \beta$-induced morphological damage, cell injury in a concentration-dependent manner and myricetin 
Fig. 7 Effective pathway of myricetin in inhibiting inflammation

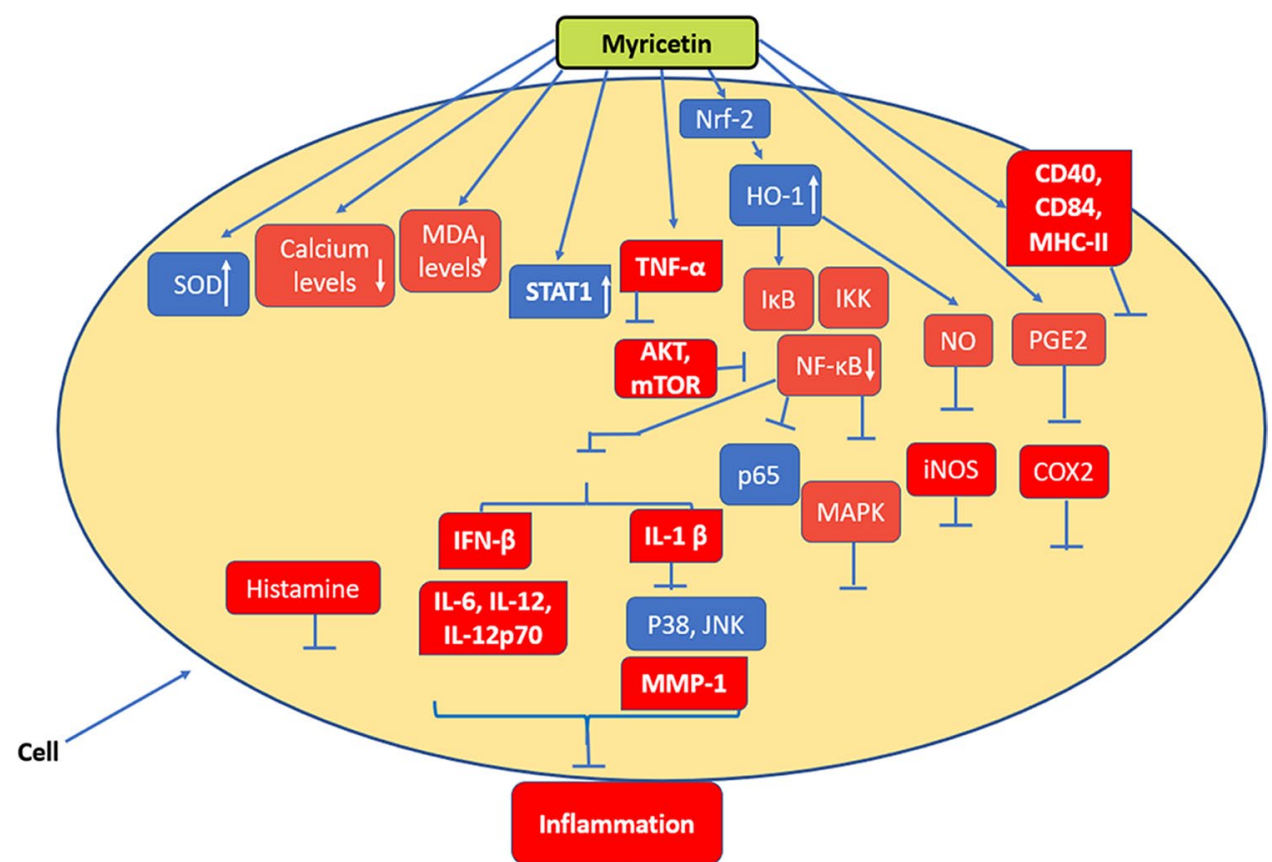

was found to supress $A \beta_{1-42}$ and $A \beta_{1-40}$ levels, inhibited the aggregation of $A \beta_{1-42}$, and inhibited structural change of $A \beta$ from random coil to $\beta$ sheet [107]. Neurotransmitter glutamate is known to be involved in neurodegenerative diseases including ischemia and Alzheimer's disease. Myricetin treatment inhibited glutamate-induced cytotoxicity, $\mathrm{Ca}^{2+}$ overload, ROS generation, caspase-3 activity, and apoptosis [106]. Imbalance in the proteostasis may lead to the progression of neurodegenerative diseases and protein conformational disorders. Myricetin treatment increases HSF1, Hsp70, and E6-AP protein expression that are associated with protein quality control (PQC) mechanism and can reduce aggregation of mutant SOD1 (SOD1-G37R), a mutant $\alpha$-Synuclein (S87A) protein, and expanded (EGFP-HDQ74, ataxin-3(84Q)) polyglutamine proteins and inhibited glutamate in vitro [49]. The role of myricetin in positively controlling the neurodegenerative diseases is shown in Fig. 8.
Fig. 8 Protective pathway of myricetin in neurodegenerative conditions

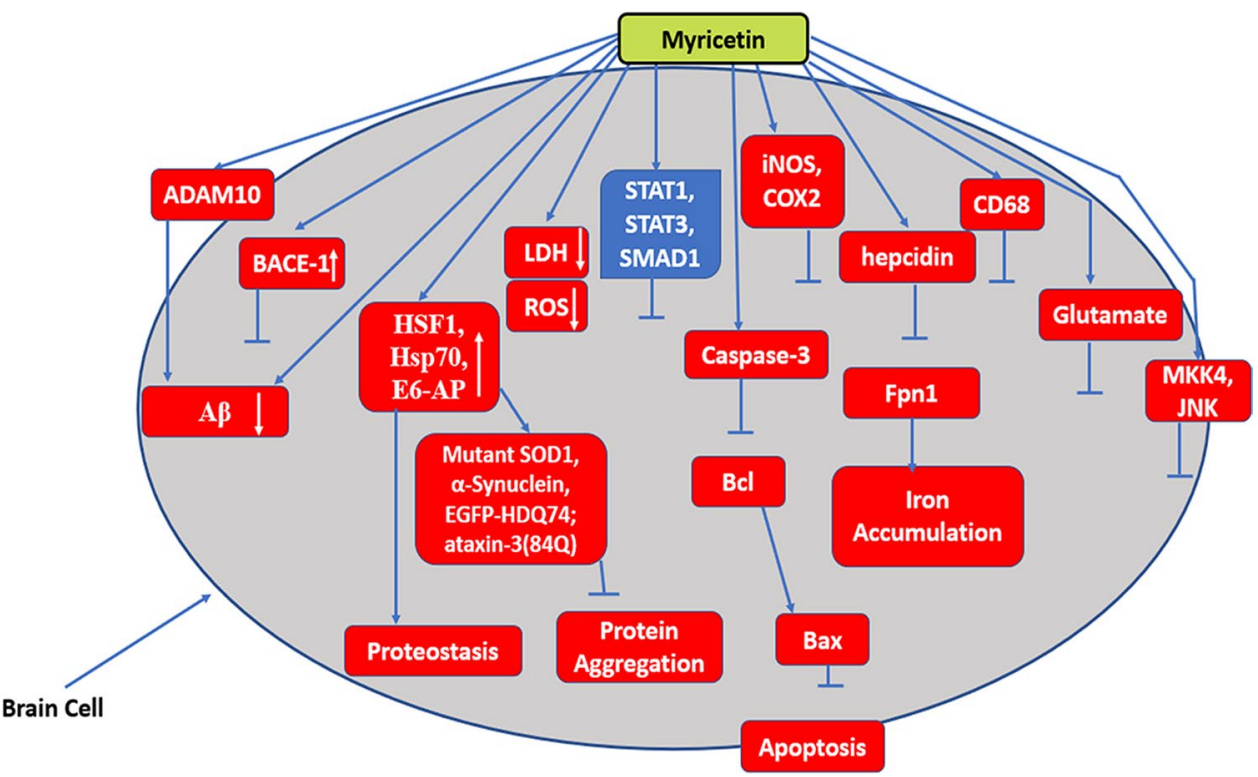




\section{Conclusion}

The role of free radicals in distressing the cellular homeostasis, in modulating biomolecules, and in inducing different kinds of cellular dysfunctions related to various diseases is well established. Myricetin is a flavanol found in berries, fruits, and vegetables and is known for its antioxidant activities. Chronic low-dose exposure to oxidants leads to cancer, and myricetin was observed to improve the antioxidant status in cancer cells, thereby offering protection. In the case of myocardial dysfunction, the different types of inflammatory cytokines responsible for causing the tissue damage were shown to be lowered when treated with myricetin. Myricetin has been shown to reduce platelet aggregation by reducing the fibrinogen binding and alpha granule secretion. In the case of viral replication, myricetin has exhibited its inhibitory role. In neurodegenerative diseases as well as inflammation caused due to various metabolic activities and diseases, myricetin has shown its positive effect. Apart from the positive effects, myricetin also shows the prooxidant effect by producing $\mathrm{H}_{2} \mathrm{O}_{2}$ due to its autooxidation and thereby generating free radicals by Fenton's reaction participation. Thus, myricetin has a dual role as protective against many diseases as well as prooxidant activity. We hypothesize that myricetin can be utilized as an antioxidant in an oxidative stress environment and it might show cell death inducing properties if it is used in combination with metal ions. To conclude the protective effect of myricetin, clinical studies followed by additional in vivo research is needed.

Acknowledgements The authors are grateful to Chettinad Academy of Research and Education for supporting the project. We also offer sincere thanks to the Council of Scientific and Industrial Research (CSIR), INDIA, for the grant with Scheme No. 01(2868)/17/EMR-II.

Author Contributions All the authors have equally contributed for concept designing, literature searching, and manuscript writing. KG and AG finalized the draft.

Funding The research was supported by Council of Scientific and Industrial Research (CSIR) India, Scheme No. 01(2868)/17/EMR-II.

Data Availability Not applicable

Code Availability Not applicable

\section{Declarations}

Ethics Approval Not applicable

Consent to Participate Not applicable

Consent for Publication All the authors have given the consent to publish.

Conflict of Interest The authors declare no competing interests.

\section{References}

1. Ahmad TA, Fazal F, Rahman A, Hadi SM, Parish JH. Activities of flavonoids for the cleavage of DNA in the presence of $\mathrm{Cu}(\mathrm{II})$ : correlation with generation of active oxygen species. Carcinogenesis. 1992;13:605-8.

2. Ali MC, Chen J, Zhang H, Li Z, Zhao L, Qiu H. Effective extraction of flavonoids from Lycium barbarum $L$. fruits by deep eutectic solvents-based ultrasound-assisted extraction. Talanta. 2019;203:16-22.

3. Arredondo M, Núñez MT. Iron and copper metabolism. Mol Aspects Med. 2005;26:313-27.

4. Austin CA, Patel S, Ono K, Nakane H, Fisher LM. Site-specific DNA cleavage by mammalian DNA topoisomerase II induced by novel flavone and catechin derivatives. Biochem J. 1992;282:883-9.

5. Barzegar A. Antioxidant activity of polyphenolic myricetin in vitro cell-free and cell-based systems. Mol Biol Res Commun. 2016;5:87-95.

6. Biela M, Rimarčík J, Senajová E, Kleinová A, Klein E. Antioxidant action of deprotonated flavonoids: thermodynamics of sequential proton-loss electron-transfer. Phytochem. 2020;180:112528.

7. Boriero D, Carcereri de Prati A, Antonini L, Ragno R, Sohji K, Mariotto S, Butturini E. The anti-STAT1 polyphenol myricetin inhibits M1 microglia activation and counteracts neuronal death. FEBS J. 2020;288:2347-59.

8. Bose (Girigoswami) K, Bhaumik G, Ghosh R. Chronic low dose exposure to hydrogen peroxide changes sensitivity of V79 cells to different damaging agents. Ind J Exp Biol. 2003;41:832-6.

9. Bose (Girigoswami) K, Bhaumik G, Ghosh R. Induced resistance in cells exposed to repeated low doses of $\mathrm{H}_{2} \mathrm{O}_{2}$ involves enhanced activity of antioxidant enzymes. Cell Biol Int. 2005;29:761-7.

10. Bose (Girigoswami) K, Ghosh R. Response to $\gamma$-irradiation in V79 cells conditioned by repeated treatment with low doses of hydrogen peroxide. Radiat Environ Bioph. 2005;44:131-7.

11. Braca A, Bilia AR, Mendez J, Morelli I. Myricetin glycosides from Licania densiflora. Fitoterapia. 2001;72:182-5.

12. Braca A, Bilia A, Mendez J, Morelli I. Three flavonoids from Licania densiflora. Phytochem. 1999;51:1125-8.

13. Camoirano A, Balansky RM, Bennicelli C, Izzotti A, D'Agostini F, Flora S. Experimental databases on inhibition of the bacterial mutagenicity of 4-nitroquinoline 1-oxide and cigarette smoke. Mutation Res. 1994;317:89-109.

14. Canada AT, Giannella E, Nguyen TD, Mason RP. The production of reactive oxygen species by dietary flavonols. Free Radic Biol Med. 1990;9:441-9.

15. Chen S, Fan B. Myricetin protects cardiomyocytes from LPSinduced injury. Herz. 2018;43:265-74.

16. Cho BO, Yin HH, Park SH, Byun EB, Ha HY, Jang SI. Antiinflammatory activity of myricetin from Diospyros lotus through suppression of NF- $\mathrm{KB}$ and STAT1 activation and Nrf2-mediated HO-1 induction in lipopolysaccharide-stimulated RAW264.7 macrophages. Biosci Biotechnol Bioche. 2016;80:1520-30.

17. Chobot V, Hadacek F. Exploration of pro-oxidant and antioxidant activities of the flavonoid myricetin. Redox Rep. 2011;16:242-7.

18. Choi S-M, Kim BC, Cho Y-H, Choi K-H, Chang J, Park M-S, Kim M-K, Cho K-H. Effects of flavonoid compounds on $\beta$-amyloid-peptide-induced neuronal death in cultured mouse cortical neurons. Chonnam Med J. 2014;50:45-51.

19. Chu SC, Hsieh YS, Lin JY. Inhibitory effects of flavonoids on moloney murine leukemia virus reverse transcriptase activity. J Nat Prod. 1992;55:179-83.

20. Ci Y, Zhang Y, Liu Y, Lu S, Cao J, Li H, Zhang J, Huang Z, Zhu $\mathrm{X}$, Gao J, Han M. Myricetin supresses breast cancer metastasis 
through downregulating the activity of matrix metalloproteinase (MMP)-2/9. Phytother Res. 2018;32:1373-81.

21. D’Ambrosio M, Bigagli E, Cinci L, Gori A, Brunetti C, Ferrini $\mathrm{F}$, Luceri C. Ethyl acetate extract from Cistus $\mathrm{x}$ incanus L. leaves enriched in myricetin and quercetin derivatives, inhibits inflammatory mediators and activates Nrf2/HO-1 pathway in LPS-stimulated RAW 264.7 macrophages. Zeitschrift Für Naturforschung C. 2020;76:79-86.

22. Daino GL, Frau A, Sanna C, Rigano D, Distinto S, Madau V, Esposito F, Fanunza E, Bianco G, Taglialatela SO, Zinzula L, Maccioni E, Corona A, Tramontano E. Identification of myricetin as Ebolavirus VP35-dsRNA interaction inhibitor through a novel fluorescence-based assay. Biochemistry. 2018;57:6367-78.

23. De S, Gopikrishna A, Keerthana V, Girigoswami A, Girigoswami $\mathrm{K}$. An overview of nano formulated nutraceuticals and its therapeutic approaches. Curr Nutr Food Sci. 2021;17:392-407.

24. De Whalley CV, Rankin SM, Hoult JRS, Jessup W, Leake DS. Flavonoids inhibit the oxidative modification of low density lipoproteins by macrophages. Biochem Pharmacol. 1990;39:1743-50.

25. Deng H, Liu S, Pan D, Jia Y, Ma ZG. Myricetin reduces cytotoxicity by suppressing hepcidin expression in MES23.5 cells. Neural Regen Res. 2021;16:1105-10.

26. Devasagayam TPA, Subramanian M, Singh BB, Ramanathan $\mathrm{R}$, Das NP. Protection of plasmid pBR322 DNA by flavonoids against single-strand breaks induced by singlet molecular oxygen. J Photoc Photobiol B. 1995;30:97-103.

27. Devi KP, Rajave T, Habtemariam S, Nabavi SF, Nabavi SM. Molecular mechanisms underlying anticancer effects of myricetin. Life Sci. 2015;142:19-25.

28. Domitrović R, Rashed K, Cvijanović O, Vladimir-Knežević S, Škoda M, Višnić A. Myricitrin exhibits antioxidant, antiinflammatory and antifibrotic activity in carbon tetrachlorideintoxicated mice. Chem Biol Interact. 2015;230:21-9.

29. Fiorucci S, Golebiowski J, Cabrol-Bass D, Antonczak S. DFT study of quercetin activated forms involved in antiradical, antioxidant, and prooxidant biological processes. J Agric Food Chem. 2007;55:903-11.

30. Flora SD, Rosenkranz HS, Klopman G. Structural basis of antimutagenicity of chemicals towards 4-nitroquinoline 1-oxide in Salmonella typhimurium. Mutagenesis. 1994;9:39-45.

31. Foo LY, Lu Y, Molan AL, Woodfield DR, McNabb WC. The phenols and prodelphinidins of white clover flowers. Phytochemistry. 2000;54:539-48.

32. Fu R-H, Liu S-P, Chu C-L, Lin Y-H, Ho Y-C, Chiu S-C, Lin S-Z. Myricetin attenuates lipopolysaccharide-stimulated activation of mouse bone marrow-derived dendritic cells through suppression of IKK/NF- $\mathrm{KB}$ and MAPK signalling pathways. J Sci Food Agr. 2012;93:76-84.

33. Gaspar RS, da Silva SA, Stapleton J, Fontelles JLd, Sousa HR, Chagas VT, Alsufyani S, Trostchansky A, Gibbins JM, Paes AM. Myricetin, the main flavonoid in Syzygium cumini leaf, is a novel inhibitor of platelet thiol isomerases PDI and ERp5. Front Pharmacol. 2020;10:1678.

34. Gaetke LM, Chow-Johnson HS, Chow CK. Copper: toxicological relevance and mechanisms. Arch Toxicol. 2014;88:1929-38.

35. Ghosh R, Girigoswami K, Guha D. Suppression of apoptosis leads to cisplatin resistance in V79 cells subjected to chronic oxidative stress. Ind J Biochem Biophys. 2012;49:363-70.

36. Ghosh R, Girigoswami K. NADH dehydrogenase subunits are overexpressed in cells exposed repeatedly to $\mathrm{H}_{2} \mathrm{O}_{2}$. Mutat Res. 2008;638:210-5

37. Ha TK, Jung I, Kim ME, Bae SK, Lee JS. Anti-cancer activity of myricetin against human papillary thyroid cancer involves mitochondrial dysfunction-mediated apoptosis. Biomed Pharmacother. 2017;91:378-84.
38. Häkkinen SH, Kärenlampi SO, Heinonen IM, Mykkänen HM, Törrönen AR. Content of the flavonols quercetin, myricetin, and kaempferol in 25 edible berries. J Agric Food Chem. 1999;47:2274-9.

39. Halliwell B, Murcia MA, Chirico S, Aruom OI. Free radicals and antioxidants in food and in vivo: what they do and how they work? Crit Rev Food Sci Nutr. 1995;35:7-20.

40. Hanasaki Y, Ogawa S, Fuku S. The correlation between active oxygens scavenging and antioxidative effects of flavonoids. Free Radic Biol Med. 1994;16:845-50.

41. Harris T, Jideani V, Roes-Hill ML. Flavonoids and tannin composition of Bambara groundnut (Vigna subterranea) of Mpumalanga, South Africa. Heliyon. 2018;4:e00833.

42. Huamán-Castilla NL, Mariotti-Celis MS, Pérez-Correa JR. Polyphenols of Carménère grapes. Mini-Rev Org Chem. 2017;14:176-86.

43. Huang H, Chen AY, Ye X, Li B, Rojanasakul Y, Rankin GO, Chen YC. Myricetin inhibits proliferation of cisplatin-resistant cancer cells through a p53-dependent apoptotic pathway. Int J Oncol. 2015;47:1494-502.

44. Hunter CKK, Crosbie L, Gordon MJ, Dul'ta-Roy AK. Modulation of human platelet function by food flavonoids. Biochem Soc Trans. 1996;24:197S.

45. Jackson MJ. Free radicals generated by contracting muscle: byproducts of metabolism or key regulators of muscle function? Free Radic. Biol Med. 2008;44:132-41.

46. Jianga M, Zhua M, Wangb L, Yu S. Anti-tumor effects and associated molecular mechanisms of myricetin. Biomed Pharmacother. 2019;120:109506.

47. Jo S, Kim S, Shin DH, Kim MS. Inhibition of African swine fever virus protease by myricetin and myricitrin. J Enzyme Inhib Med Chem. 2020;35:1045-9.

48. Jomová K, Hudecova L, Lauro P, Simunkova M, Alwasel SH, Alhazza IM, Valko M. A switch between antioxidant and prooxidant properties of the phenolic compounds myricetin, morin, 3',4'-dihydroxyflavone, taxifolin and 4-hydroxy-coumarin in the presence of copper (ii) ions: a spectroscopic, absorption titration and DNA damage study. Molecules. 2019;24:4335.

49. Joshi V, Mishra R, Upadhyay A, Amanullah A, Poluri KM, Singh S, ..., Mishra A (2019) Polyphenolic flavonoid (Myricetin) upregulated proteasomal degradation mechanisms: eliminates neurodegenerative proteins aggregation. J Cell Physiol 234: 20900-20914

50. Jurado J, Alejandre-Duran E, Alonso-Moraga A, Pueyo C. Study on the mutagenic activity of 13 bioflavonoids with the Salmonella Ara test. Mutagenesis. 1991;6:289-95.

51. Justino GC, Vieira AJSC. Antioxidant mechanisms of quercetin and myricetin in the gas phase and in solution - a comparison and validation of semi-empirical methods. J Mol Model. 2010;16:863-76.

52. Kalff J, Robinson R. XXVIII.-A synthesis of myricetin and of a galangin monomethyl ether occurring in galanga root. J Chem Soc Trans. 1925;127:181-4.

53. Kassouf N, Kay CWM, Volkov A, Chiang SC, Birch-Machin MA, El-Khamisy SF, Haywood RM. UVA-induced carboncentred radicals in lightly pigmented cells detected using ESR spectroscopy. Free Radic Biol Med. 2018;126:153-65.

54. Keum YS, Jeong YJ. Development of chemical inhibitors of the SARS corona virus: viral helicase as a potential target. Biochem Pharmacol. 2012;84:1351-8.

55. Klein E, Lukeš V, Ilčin M. DFT/B3LYP study of tocopherols and chromans antioxidant action energetics. Chem Phys. 2007;336:51-7.

56. Knickle A, Fernando W, Greenshields AL, Rupasinghe HPV, Hoskin DW. Myricetin-induced apoptosis of triple-negative breast cancer cells is mediated by the iron dependent generation 
of reactive oxygen species from hydrogen peroxide. Food Chem Toxicol. 2018;118:154-67.

57. Kuo PL. Myricetin inhibits the induction of anti-Fas IgM-, tumor necrosis factor-alpha- and interleukin-1beta-mediated apoptosis by Fas pathway inhibition in human osteoblastic cell line MG-63. Life Sci. 2005;77:2964-76.

58. Landolfi R, Mower RL, Steiner M. Modification of platelet function and arachidonic acid metabolism by bioflavonoids. Biochem Pharmacol. 1984;33:1520-30.

59. Laughton MJ, Evans PJ, Moroney MA, Hoult JRS, Halliwell B. Inhibition of mammalian 5-lipoxygenase and cyclo-oxygenase by flavonoids and phenolic dietary additives relationship to antioxidant activity and to iron ion- reducing ability. Biochem Pharmacol. 1991;42:1673-81.

60. Laughton MJ, Halliwell B, Evans PJ, Hoult JR. Antioxidant and pro-oxidant actions of the plant phenolics quercetin, gossypol and myricetin. Effects on lipid peroxidation, hydroxyl radical generation and bleomycin-dependent damage to DNA. Biochem Pharmacol. 1989;38:2859-65.

61. Lee DH, Lee CS. Flavonoid myricetin inhibits TNF- $\alpha$-stimulated production of inflammatory mediators by suppressing the Akt, $\mathrm{mTOR}$ and NF- $\mathrm{BB}$ pathways in human keratinocytes. Eur J Pharmacol. 2016;784:164-72.

62. Lee TH, Qiu F, Waller GR, Chou CH. Three New Flavonol Galloylglycosides from Leaves of Acacia confusa. J Nat Prod. 2000;63:710-2.

63. Lee YS, Choi EM. Myricetin inhibits IL-1 $\beta$-induced inflammatory mediators in SW982 human synovial sarcoma cells. Int Immunopharmacol. 2010;10:812-4.

64. Lescano CH, Lima FF, Mendes-Silvério CB, Justo AFO, Baldivia DS, Vieira CP, Sanjinez-Argandoña EJ, Cardoso CAL, Mónica FZ, Oliveira IP. Effect of polyphenols from Campomanesia adamantium on platelet aggregation and inhibition of cyclooxygenases: molecular docking and in vitro analysis. Front Pharmacol. 2018;9:617.

65. Li M, Chen J, Yu X, Xu S, Li D, Zheng Q, Yin Y. Myricetin suppresses the propagation of hepatocellular carcinoma via downregulating expression of YAP. Cells. 2019;8:358.

66. Lia W, Xua C, Haob C, Zhang Y, Wang Z, Wang S, Wang W. Inhibition of herpes simplex virus by myricetin through targeting viral $\mathrm{gD}$ protein and cellular EGFR/PI3K/Akt pathway. Antiviral Res. 2020;177:104714.

67. Liao HH, Zhang N, Meng YY, Feng H, Yang JJ, Li WJ, Chen S, Wu HM, Deng W, Tang QZ. Myricetin alleviates pathological cardiac hypertrophy via TRAF6/TAK1/MAPK and Nrf2 signalling pathway. Oxid Med Cell Longev. 2019;2019:6304058.

68. Lim HJ, Nguyen TTH, Kim NM, Park JS, Jang TS, Kim D. Inhibitory effect of flavonoids against NS2B-NS3 protease of ZIKA virus and their structure activity relationship. Biotechnol Lett. 2016;39:415-21.

69. Lin LC, Chou CJ. Flavonoids and Phenolics from Limonium sinense. Planta Med. 2000;66:382-3.

70. Litwinienko G, Ingold KU. Solvent effects on the rates and mechanisms of reaction of phenols with free radicals. Acc Chem Res. 2007;40:222-30.

71. Lushchak VI. Free radicals, reactive oxygen species, oxidative stress and its classification. Chem Biol Interact. 2014;224:164-75.

72. Lyu SY, Rhim JY, Park WB. Antiherpetic activities of flavonoids against herpes simplex virus type 1 (HSV-1) and type 2 (HSV-2) in vitro. Arch Pharm Res. 2005;28(11):1293-301.

73. Mandic L, Sadzak A, Erceg I, Baranovic G, Segota S. The finetuned release of antioxidant from superparamagnetic nanocarriers under the combination of stationary and alternating magnetic fields. Antioxidants. 2021;10:1212.
74. Mani JS, Johnson JB, Steel JC, Broszczak DA, Neilsen PM, Walsh KB, Naiker M. Natural product-derived phytochemicals as potential agents against coronaviruses: a review. Virus Res. 2020;284:197989.

75. Melzig MF, Henke K. Inhibition of Thrombin Activity by Selected Natural Products in Comparison to Neutrophil Elastase. Planta Med. 2005;71:787-9.

76. Michael GLH, Edith JMF, Peter CHH, Martijn BK, Daan K. Dietary antioxidant flavonoids and risk of coronary heart disease: the Zutphen Elderly Study. Lancet. 1993;342:1007-11.

77. Miean KH, Mohamed S. Flavonoid (myricetin, quercetin, kaempferol, luteolin, and apigenin) content of edible tropical plants. J Agric Food Chem. 2001;49:3106-12.

78. Mira L, Tereza Fernandez M, Santos M, Rocha R, Helena Florêncio M, Jennings KR. Interactions of flavonoids with iron and copper ions: a mechanism for their antioxidant activity. Free Radic Res. 2002;36:1199-208.

79. Molina-Jimenez MF, Sanchez-Reus MI, Benedi J. Effect of fraxetin and myricetin on rotenone-induced cytotoxicity in $\mathrm{SH}-$ SY5Y cells: comparison with $\mathrm{N}$-acetylcysteine. Eur J Pharmacol. 2003;472:81-7.

80. Nagai S, Ohara K, Mukai K. Kinetic study of the quenching reaction of singlet oxygen by flavonoids in ethanol solution. J Phys Chem B. 2005;109:4234-40.

81. National Center for Biotechnology Information, 2021. PubChem Compound Summary for CID 5281672, Myricetin. https://pubch em.ncbi.nlm.nih.gov/compound/Myricetin

82. Neha K, Haider MR, Pathak A, Yar MS. Medicinal prospects of antioxidants: a review. Eur J Med Chem. 2019;178:687-704.

83. Ong KC, Khoo HE. Biological effects of myricetin. Gen Pharmacol. 1997;29:121-6.

84. Ono K, Nakane H. Mechanisms of inhibition of various cellular DNA and RNA polymerases by several flavonoids. J Biochem. 1990;108:609-13.

85. Ono K, Nakane H, Fukushima M, Chermann JC, Rarre-Sinouss F. Differential inhibitory effects of various flavonoids on the activities of reverse transcriptase and cellular DNA and RNA polymerases. Eur J Biochem. 1990;190:469-76.

86. Onstantinou A, Mehta R, Rwan C. Flavonoids as DNA topoisomerase antagonists and poisons: structure-activity relationships. J Nat Prod. 1995;58:217-25.

87. Osman HE, Maalej N, Shanmuganayagam D, Folts JD. Grape juice but not orange or grapefruit juice inhibits platelet activity in dogs and monkeys (Macaca fasciularis). J Nutr. 1998;128:2307-12.

88. Oyama Y, Fuchs PA, Katayama N, Noda K. Myricetin and quercetin, the flavonoid constituents of Ginkgo biloba extract, greatly reduce oxidative metabolism in both resting and $\mathrm{Ca}$ ${ }^{2+}$-loaded brain neurons. Brain Res. 1994;635:125-9.

89. Pantopoulos K, Porwal SK, Tartakoff A, Devireddy L. Mechanisms of mammalian iron homeostasis. Biochemistry. 2012;51:5705-24.

90. Park H-H, Lee S, Son H-Y, Park S-B, Kim M-S, Choi E-J, et al. Flavonoids inhibit histamine release and expression of proinflammatory cytokines in mast cells. Arch Pharm Res. 2008;31:1303-11.

91. Pasetto S, Pardi V, Murata RM. Anti-HIV-1 activity of flavonoid myricetin on HIV-1 infection in a dual-chamber in vitro model. PLoS One. 2014;9:e115323.

92. Perez-Vizcaino F, Fraga CG. Research trends in flavonoids and health. Arch Biochem Biophys. 2018;646:107-12.

93. Procházková $\mathrm{D}$, Boušová I, Wilhelmová N. Antioxidant and prooxidant properties of flavonoids. Fitoterapia. 2011;82:513-23.

94. Qiu Y, Cong N, Liang M, Wang Y, Wang J. Systems pharmacology dissection of the protective effect of myricetin against acute 
ischemia/reperfusion-induced myocardial injury in isolated rat heart. Cardiovasc Toxicol. 2017;17:277-86.

95. Rajendran P, Maheshwari U, Muthukrishnan A, Muthuswamy R, Anand K, Ravindran B, Dhanaraj P, Balamuralikrishnan B, Chang SW, Chung WJ. Myricetin: versatile plant-based flavonoid for cancer treatment by inducing cell cycle arrest and ROS-reliant mitochondria-facilitated apoptosis in A549 lung cancer cells and in silico prediction. Mol Cell Biochem. 2020;476:57-68.

96. Ramanathan L, Das NP. Inhibitory effects of some natural products on metal-induced lipid oxidation in cooked fish. Biol Trace Elem Res. 1992;34:35-44.

97. Rao KV, Seshadri TR. Nuclear oxidation in flavones and related compounds. Proc Indian Acad Sci. 1948;27:375.

98. Roedig-Penman A, Gordon MH. Antioxidant properties of myricetin and quercetin in oil and emulsions. J Amer Oil Chem Soc. 1998;75:169-80.

99. Roehrs M, Valentini J, Paniz C, Moro A, Charão M, Bulcão R, Freitas F, Brucker N, Duarte M, Leal M, Burg G, Grune T, Garcia SC. The relationships between exogenous and endogenous antioxidants with the lipid profile and oxidative damage in hemodialysis patients. BMC Nephrol. 2011;12:59.

100. Sadžak A, Vlašić I, Kiralj Z, Batarelo M, Oršolić N, Jazvinšćak Jembrek M, Kušen I, Šegota S. Neurotoxic effect of flavonol myricetin in the presence of excess copper. Molecules. 2021;26:845.

101. Sahu SC, Gray GC. Interactions of flavonoids, trace metals, and oxygen: nuclear DNA damage and lipid peroxidation induced by myricetin. Cancer Lett. 1993;70:73-9.

102. Salvamani S, Gunasekaran B, Shaharuddin NA, Ahmad SA, Shukor MY. Anti-atherosclerotic effects of plant flavonoids. Biomed Res Int. 2014;2014:480258.

103. Semwal DK, Semwal RB, Combrinck S, Viljoen A. Myricetin: a dietary molecule with diverse biological activities. Nutrients. 2016;8:90.

104. Sies H. Oxidative stress: impact in redox biology and medicine. Arch Med Biomed Res. 2015a;2:146-50.

105. Sies H. Oxidative stress: a concept in redox biology and medicine. Redox Biol. 2015b;4:180-3.

106. Shimmyo Y, Kihara T, Akaike A, Niidome T, Sugimoto H. Three distinct neuroprotective functions of myricetin against glutamateinduced neuronal cell death: involvement of direct inhibition of caspase-3. J Neurosci Res. 2008a;86:1836-45.

107. Shimmyo Y, Kihara T, Akaike A, Niidome T, Sugimoto H. Multifunction of myricetin on A beta: neuroprotection via a conformational change of A beta and reduction of A beta via the interference of secretases. J Neurosci Res. 2008b;86:368-77.

108. Tavsan Z, Kayali HA. Flavonoids showed anticancer effects on the ovarian cancer cells: Involvement of reactive oxygen species, apoptosis, cell cycle and invasion. Biomed Pharmacother. 2019;120:109004.

109. Teo TS, Thiyagarajah P, Wong ZZ, Das NP. Does calmodulin mediate inhibition of human erythrocyte $\mathrm{Ca}^{* *}$ - pumping ATPase by myricetin? Biochem Med Metab Biol. 1991;45:209-15.

110. Thiyagarajah P, Kuttan SC, Lim SC, Teo TS, Das NP. Effect of myricetin and other flavonoids on the liver plasma membrane $\mathrm{Ca}^{2+}$ pump/ kinetics and structure-function relationships. Biochem Pharmacol. 1991;41:669-75.

111. Tolosa T, Rogez H, Silva E, Souza J. Optimization of acid hydrolysis of myricetin-3-O-rhamnoside using response surface methodology. J Braz Chem Soc. 2018;29:2475-81.

112. Tsao R. Chemistry and biochemistry of dietary polyphenols. Nutrients. 2010;2:1231-46.

113. Tseng SH, Ko DC, Ko PN, Teng CM. Inhibition of platelet aggregation by some flavonoids. Thrombosis Res. 1991;64:91-100.

114. Ueda H, Yamazaki C, Yamazaki M. A hydroxyl group of flavonoids affects oral anti-inflammatory activity and inhibition of systemic tumor necrosis factor- $\alpha$ production. Biosci Biotechnol Biochem. 2004;68:119-25.

115. Walker EH, Pacold ME, Perisic O, Stephens L, Hawkins PT, Wymann MP, Williams RL. Structural determinants of phosphoinositide 3-kinase inhibition by wortmannin, LY294002, quercetin, myricetin, and staurosporine. Mol Cell. 2000;6:909-19.

116. Wang L, Lee IM, Zhang SM, Blumberg JB, Buring JE, Sesso HD. Dietary intake of selected flavonols, flavones, and flavonoid-rich foods and risk of cancer in middle-aged and older women. Am J Clin Nutri. 2009;89:905-12.

117. Wang S-J, Tong Y, Lu S, Yang R, Liao X, Xu Y-F, Li X. Anti-inflammatory activity of myricetin isolated from Myrica rubraSieb. et Zucc. Leaves Planta Medica. 2010;76:1492-6.

118. Xiao T, Cui M, Zheng C, Wang M, Sun R, Gao D, Bao J, Ren S, Yang B, Lin J, Li X, Li D, Yang C, Zhou H. Myricetin inhibits SARS-CoV-2 viral replication by targeting $\mathrm{M}^{\text {pro }}$ and ameliorates pulmonary inflammation. Front Pharmacol. 2021;12:669642.

119. Xu Q-X, Zhang Y-B, Liu X-Y, Xu W, Yang X-W. Cytotoxic heterodimers of meroterpene phenol from the fruits of Psoralea corylifolia. Phytochemistry. 2020;176:112394.

120. Yao LH, Jiang YM, Shi J, Tom as-Barber'an FA, DattaSinganusong NR, Chen SS. Flavonoids in food and their health benefits. Plant Food Hum Nutr. 2004;59:113-22.

121. Ye C, Zhang C, Huang H, Yang B, Xiao G, Kong D, Tian Q, Song Q, Song Y, Tan H, Wang Y, Zhou T, Zi X, Sun Y. The natural compound myricetin effectively represses the malignant progression of prostate cancer by inhibiting PIM1 and disrupting the PIM1/ CXCR4 interaction. Cell Physiol Biochem. 2018;48:1230-44.

122. Yu MS, Lee J, Lee JM, Kim Y, Chin YW, Jee JG, Keum YS, Jeong YJ. Identification of myricetin and scutellarein as novel chemical inhibitors of the SARS corona virus helicase, nsP13. Bioorg Med Chem Lett. 2012;22:4049-54.

123. Zang W, Wang T, Wang Y, Li M, Xuan X, Ma Y, Du Y, Liu K, Dong Z, Zhao G. Myricetin exerts anti-proliferative, anti-invasive, and pro-apoptotic effects on esophageal carcinoma EC9706 and KYSE30 cells via RSK2. Tumor Biol. 2014;35:12583-92.

124. Zhang H-Y, Sun Y-M, Wang X-L. Substituent effects on O-H bond dissociation enthalpies and ionization potentials of catechols: a DFT study and its implications in the rational design of phenolic antioxidants and elucidation of structure-activity relationships for flavonoid antioxidants. Chem Eur J. 2003;9:502-8.

125. Zhang K, Ma Z, Wang J, Xie A, Xie J. Myricetin attenuated MPP+-induced cytotoxicity by anti-oxidation and inhibition of MKK4 and JNK activation in MES23.5 cells. Neuropharmacology. 2011;61:329-35.

126. Zhang N, Feng H, Liao HH, Chen S, Yang Z, Deng W, Tang QZ. Myricetin attenuated LPS induced cardiac injury in vivo and in vitro. Phytother Res. 2018;32:459-70.

127. Zhang S, Wang L, Liu H, Zhao G, Ming L. Enhancement of recombinant myricetin on the radio sensitivity of lung cancer A549 and H1299 cells. Diagn Pathol. 2014;9:68. https://doi.org/ 10.1186/1746-1596-9-68.

128. Zhao J, Hong T, Dong M, Meng Y, Mu J. Protective effect of myricetin in dextran sulphate sodium-induced murine ulcerative colitis. Mol Med Rep. 2013;7:565-70.

129. Zheng Y-Z, Fu Z-M, Deng G, Guo R, Chen D-F. Free radical scavenging potency of ellagic acid and its derivatives in multiple H+/e- processes. Phytochemistry. 2020;180:112517.

130. Zou M, Liu H, Li J, Yao X, Chen Y, Ke C, Liu S. Structureactivity relationship of flavonoid bifunctional inhibitors against zika virus infection. Biochem Pharmacol. 2020;177:113962.

Publisher's Note Springer Nature remains neutral with regard to jurisdictional claims in published maps and institutional affiliations. 